\title{
Skrining Fitokimia dan Uji Aktivitas Antioksidan Jantung Pisang Goroho (musa acuminafe l.) Dengan Metode 1,1-diphenyl- 2-picrylhidrazyl (DPPH)
}

\author{
Widy Susanti Abdulkadir ${ }^{*}$, Hamsidar Hasan ${ }^{2}$,Ading Alamsyah ${ }^{3}$ \\ 1,2,3 Jurusan Farmasi, Fakultas Olahraga dan Kesehatan, Universitas Negeri Gorontalo, Gorontalo, Indonesia. \\ "E-mail: widi@ung.ac.id \\ Article Info: \\ Received: 14 Juli 2021 \\ in revised form: 2 Agustus 2021 \\ Accepted: 15 Agustus 2021 \\ Available Online: 30 Agustus \\ 2021

\section{Keywords:} \\ Musa acuminafe.L \\ Antioxidant \\ DPPH \\ $\mathrm{IC}_{50}$ \\ Corresponding Author: \\ Widy Susanti Abdulkadir \\ Jurusan Farmasi \\ Fakultas Olahraga dan \\ Kesehatan \\ Universitas Negeri Gorontalo \\ E-mail: widi@ung.ac.id

\begin{abstract}
Goroho banana (Musa acuminafe L.) has its own characteristics and is one of the local varieties of banana that is not widely known to people outside North Sulawesi. In addition, it is commonly used as an antioxidant. Antioxidants are substances that can improve the function of layers of blood vessels, inhibit blood platelet aggregation where it can stimulate the production of Nitric Oxide, which causes the relaxation of blood vessels and can reduce the sensitivity of Low-Density Lipoprotein (LDL) to the effects of free radicals. Therefore, this research aims to determine the chemical content and antioxidant activity of Goroho Banana (Musa acuminafe L.) by using DPPH (1,1-diphenyl-2-picrylhydrazyl) method. Besides, the extraction of samples is carried out by employing extraction graded with n-hexane, chloroform, ethyl acetate, and ethanol solvents. Findings reveal that Goroho banana (Musa acuminafe L.) peel extract contains Alkaloid and Flavonoid compounds. Meanwhile, the value of antioxidant activity indicates that the $\mathrm{IC}_{50}$ value for n-hexane, chloroform, ethyl acetate, and ethanol extracts are 6.38, 5.48, $5.11,4.19 \mathrm{ug} / \mathrm{ml}$, respectively. In conclusion, the $\mathrm{IC}_{50}$ value discloses that the antioxidant activity is in a strong category.
\end{abstract}

Copyright () 2021 IJPE-UNG UNG This open access article is distributed under a Creative Commons Attribution (CC-BY-NC-SA) 4.0

International license.

How to cite (APA $6^{\text {th }}$ Style):

Abdulkadir.W.S.,Hasan.H. Alamyah.A., (2021). Skrining fitokimia dan uji aktivitas antiokaisan jantung pisang goroho (Musa acuminafe L.) dengan metode 1,1-diphenyl-2-picylhydrazyl (DPPH). Indonesian Journal of Pharmaceutical (e-Journal),1(3), 136-141. 


\begin{abstract}
ABSTRAK
Pisang goroho (Musa acuminafe L.) memiliki ciri khas tersendiri dan merupakan salah satu jenis pisang varietas lokal yang belum banyak dikenal masyarakat diluar Sulawesi Utara dan dimanfaatkan sebagai antioksidan. Antioksidan mampu memperbaiki fungsi lapisan pada pembulu darah, menghambat penggumpalan keping-keping darah yang dimana dapat merangsang produksi Nitrit Oksida yang menyebabkan relaksasi pembulu darah dan dapat mengurangi kepekaan Low Density Lipoprotein (LDL) terhadap pengaruh radikal bebas. Penelitian ini bertujuan untuk mengetahui kandungan kimia dan aktivitas antioksidan jantung pisang goroho (Musa acuminafe L.) dengan menggunakan metode 1,1-Diphenyl-2-Picrylhydrazyl (DPPH). Ekstraksi sampel dilakukan dengan metode ekstraksi bertingkat menggunakan pelarut n-heksan, kloroform, etil asetat dan etanol. Hasil penelitian menunjukkan ekstrak kulit Pisang goroho (Musa acuminafe L.) mengandung senyawa Alkaloid dan Flavonoid. Nilai aktivitas antioksidan menunjukkan nilai $\mathrm{IC}_{50}$ ekstrak N-heksan, kloroform, etil asetat, dan etanol berturut-turut sebesar $6.38,5.48,5.11,4.19 \mu \mathrm{g} / \mathrm{mL}$. Nilai $\mathrm{IC}_{50}$ menunjukkan bahwa aktivitas antioksidan adalah kategori kuat.
\end{abstract}

Kata Kunci: Jantung Pisang Goroho , Antioksidan , DPPH , IC 50.

\title{
1. Pendahuluan
}

Seiring dengan semakin tingginya tingkat kesadaran masyarakat akan kesehatan, penggunaan obat yang berasal dari tumbuhan atau pengobatan dengan cara tradisional juga mengalami peningkatan, hal ini mungkin disebabkan karena lebih murah dan minim efek samping dibanding dengan menggunakan obat-obat modern atau obat-obatan dari bahan kimia. Maka dari itu penggunaan obat dari bahan alam bisa digunakan dalam bentuk sediaan tunggal maupun ramuan untuk berbagai macam penyakit [2].

Menurut pengalaman empiris oleh masyarakat kabupaten bolaang mongondow dan kotamobagu bahwa jantung pisang goroho (Musa acuminafe L.) dipercaya berkhasiat sebagai antihipertensi sehingga sebagian masyarakat mengolah jantung pisang goroho untuk dikonsumsi sebagai obat penurun darah tinggi (hipertensi)[14], hal ini memungkinkan kadar antioksidan yang terkandung dalam jantung pisang sangat tinggi [10]., antioksidan mampu memperbaiki fungsi lapisan pada pembulu darah, menghambat penggumpalan keeping-keping darah yang dimana dapat merangsang produksi Nitrit Oksida yang menyebabkan relaksasi pembulu darah dan dapat mengurangi kepekaan Low Density Lipoprotein (LDL) terhadap pengaruh radikal bebas [3].

Berdasarkan hal tersebut akan dilakukan penelitian skrining fitokimia dan uji aktifitas antioksidan jantung pisang goroho (Musa acuminafe L.) dengan Metode 1,1-Difenil-2Picrylhydrazin (DPPH) untuk mengetahui senyawa metabolit sekunder yang terdapat dalam jantung pisang goroho serta uji aktifitas antioksidan dengan metode DPPH untuk mengetahui kemampuan ekstrak dalam menghambat radikal bebas DPPH.

\section{Metode}

Alat dan Bahan

Alat yang digunakan untuk penelitian ini yaitu batang pengaduk, blender, cawan porselin, chamber KLT, corong, evaporator, gelas kimia (pyrex), gelas ukur (pyrex), gunting, kuvet (Quartz), tabung reaksi, lampu UV $366 \mathrm{~nm}$, maserator, neraca analitik, penggaris, pensil, pipa kapiler, pipet tetes, pipet mikro (Perkin elmer), rak tabung reaksi, spatula, spektrofotometer UVVis (Perkin elmer), vial, wadah steinlis, wadah maserasi. 
Bahan yang digunakan pada penelitian ini yaitu alkohol 70\%, aluminium foil, asam klorida, asam sulfat pekat, aquades, DPPH, etanol, etil asetat, ferri klorida, kertas label, kloroform, metanol, n-heksan, pereaksi dragendroff, pereaksi mayer, pereaksi wagner, preaksi shinoda, preaksi Lieberman-Burchard, simplisia Jantung Pisang Goroho (Musa acuminafe L.), plat KLT.

Prosedur Penelitian

Sampel yang digunakan pada penelitian ini yaitu sampel jantung pisang goroho. Sampel dilakukan pembersihan dan dipotong kecil, selanjutnya sampel dikeringkan dan dihaluskan menggunakan blender untuk memperoleh serbuk kering. Sampel yang telah dihaluskan diekstraksi menggunakan metode maserasi bertingkat memakai pelarut n-heksan, kloroform, etil asetat, dan etanol. Pada proses awal, sampel diekstraksi menggunakan n-heksan sebanyak 1500 mL selama $3 \times 24$ jam. Hasil maserasi pelarut n-heksan kemudian disaring dan filtratnya di pekatkan menggunakan evaporator sedangkan residu diangin-anginkan sampai kering kemudian diekstraksi kembali dengan pelarut kloroform sebanyak $1500 \mathrm{~mL}$ selama 3 × 24 jam. Hasil maserasi pelarut kloroform kemudian dilakukan penyaringan dan filtratnya dipekatkan menggunakan evaporator, sedangkan residu diangin-anginkan sampai kering kemudian diekstraksi kembali dengan etil asetat sebanyak $1500 \mathrm{~mL}$ selama $3 \times 24$ jam. Hasil maserasi pelarut etil asetat dilakukan penyaringan filtrat kemudian dipekatkan dengan evaporator sedangkan residunya diangin-anginkan kembali sampai kering kemudian diekstraksi kembali dengan pelarut etanol sebanyak $1500 \mathrm{~mL}$ selama $3 \times 24$ jam. Hasil maserasi pelarut etanol dilakukan penyaringan dan filtrat hasil dipekatkan menggunakan evaporator sampai menjadi ekstrak kental.

\section{Skrining Fitokimia}

Pengujian komponen kimia ekstrak jantung piang goroho (Musa acuminafe. L) meliputi uji Alkaloid, Flavonoid, Saponin, Steroid, Tanin dan Triterpenoid.

\section{Uji Aktivitas Antioksidan}

Uji aktivitas antioksidan menggunakan metode DPPH. Pembuatan Larutan DPPH 0,1 mM dilakukan dengan menimbang 0,0019 gram DPPH dan dilarutkan metanol p.a lalu dimasukkan pada labu ukur $50 \mathrm{~mL}$ Kemudian larutan DPPH tersebut ditentukan panjang gelombang maksimumnya menggunakan spektrofotometer UV-Vis. Pada penelitian ini pembuatan larutan uji ekstrak jantung pisang goroho menggunakan seri konsentrasi 5, 10, 25, 50, $100 \mathrm{ppm}$. Masing-masing ekstrak jantung pisang goroho yang telah dibuat 5 seri konsentrasi diambil $2 \mathrm{~mL}$ dan ditambahkan dengan larutan DPPH sebanyak $2 \mathrm{~mL}$, lalu dihomogenkan serta diinkubasi selama 30 menit dalam ruang gelap. Kemudian diukur nilai absorbansinya pada panjang gelombang DPPH. Selanjutnya dihitung nilai persen inhibisi dari masing - masing ekstrak dan nilai IC $_{50}$ (Inhibitory Concenctration).

3. Hasil dan Pembahasan

Preparasi Sampel

Dalam penelitian ini mengunkan jantung pisang goroho yaitu ujung bunga pisang yang tersisa saat bagian lainnya tumbuh menjadi buah pisang. Sampel jantung pisang tersebut dikumpulkan dan mengalami proses pencucian dan sortasi untuk dilanjutkan ke tahap perajangan. Sampel jantung pisang dipotong menjadi ukuran yang lebih kecil dan dikeringkan dengan cara diangin-anginkan. Pengeringan ini dilakukan untuk menghilangkan kadar air dari sampel jantung pisang yang telah dijadikan simplisia tersebut. Sampel yang sudah dikeringkan kemudian diserbukan. Tujuan penyerbukan tersebut untuk memperbesar luas permukan dari sampel, yang akan memperbesar kontak antara pelarut dan sampel [4]. 
Proses ekstraksi jantung pisang goroho dilakukan dengan metode maserasi. Maserasi dipilih karena proses pengerjaanya yang mudah dan peralatan yang digunakan cukup sederhana. Proses maserasi dilakukan secara bertingkat menggunakan empat pelarut yang berbeda yaitu $n$-heksan, kloroform, etil asetat, dan etanol agar komponen-komponen yang bersifat non-polar diharapkan tersari dalam pelarut $n$-heksan dan kloroform, komponen kimia yang bersifat semi polar tersari dalam etil asetat dan komponen kimia yang bersifat polar dapat tersari dalam etanol. Hasil proses ekstraksi kemudian dipekatkan hingga menjadi ekstrak kental.

Tabel 1. Persen Rendamen Ekstrak

\begin{tabular}{cccc}
\hline Ekstrak & Berat Sampel Awal (gr) & Berat Ekstrak (gr) & \% Rendamen \\
\hline N-heksan & 500 & 56 & 11,2 \\
Kloroform & 440 & 48 & 10,9 \\
Etil Asetat & 389 & 47 & 12,8 \\
Etanol & 336 & 40 & 11,9 \\
\hline
\end{tabular}

Berdasarkan hasil yang didapatkan bahwa masing-masing rendamen pada tiap-tiap pelarut berkisar 10-15\%. Menurut [12], yang menyatakan bahwa persen nilai rendamen yang baik didapatkan masuk dalam range persen rendamen yaitu 10-15\%. Rendahnya persen rendamen yang didapatkan dapat dipengaruhi oleh lama ekstraksi Menurut [8], yang menyatakan bahwa faktor yang memungkinkan dapat mempengaruhi nilai rendemen yang dihasilkan yaitu metode ekstraksi yang digunakan, ukuran partikel sampel, kondisi dan waktu penyimpanan, lama waktu ekstraksi, perbandingan jumlah sampel terhadap jumlah pelarut yang digunakan dan jenis pelarut yang digunakan. [6], menyatakan bahwa semakin lama waktu ekstraksi, semakin tinggi rendemen yang diperoleh, karena kesempatan bereaksi antara bahan dengan pelarut semakin lama sehingga proses penetrasi pelarut kedalam sel bahan semakin baik yang menyebabkan semakin banyak senyawa yang berdifusi keluar sel.

Hasil Uji Skrining Fitokimia

Tabel 2. Hasil Skrining Fitokimia Ekstrak Jantung Pisang Goroho

\begin{tabular}{cccccc}
\hline Metabolit & \multirow{2}{*}{ Reagen } & \multicolumn{5}{c}{ Ekstrak } \\
\cline { 2 - 6 } Sekunder & N-Heksan & Kloroform & Etil Asetat & Etanol \\
\hline Alkaloid & Pereaksi Dragendroff & + & + & + & - \\
Flavonoid & Serbuk Mg + HCl & - & - & + & + \\
Saponin & Aquadest & - & - & - & - \\
& $\begin{array}{c}\text { Pereaksi Lieberman } \\
\text { Steroid }\end{array}$ & - & - & - & - \\
Tanin & Burchad $_{\text {FeCl } 1 \%}$ & - & - & - & - \\
Triterpenoid & $\begin{array}{c}\text { Pereaksi Lieberman } \\
\text { Burchad }\end{array}$ & - & - & - & - \\
\hline
\end{tabular}

Hasil skrining firokimia menunjukkan bahwa senyawa yang terkandung dalam ekstrak jantung pisang goroho yaitu Alkaloid dan Flavonoid.

Uji Aktivitas Antioksidan

Uji aktivitas antioksidan Jantung Pisang Goroho (Musa acuminafe) dilakukan dengan menggunakan metode penangkapan radikal bebas DPPH (2,2-difenil-1-pikrilhidrazil). Metode DPPH dipilih karena merupakan metode sederhana, mudah, cepat dan peka serta hanya memerlukan sedikit sampel untuk mengevaluasi aktivitas antioksidan dari senyawa bahan alam [11].

Ekstrak jantung pisang goroho yang telah dibuat seri konsentrasi ditambahkan dengan larutan DPPH 0,1 mM dan di inkubasi selama 30 menit. Tujuan di inkubasi selama 30 menit 
karena reaksi berjalan lambat sehingga sampel membutuhkan waktu untuk dapat bereaksi dengan dengan radikal bebas. Proses berjalannya reaksi tersebut ditandai dengan perubahan warna sampel jantung pisang goroho (Musa acuminafe) yang awalnya ungu menjadi warna kuning. Perubahan warna ini menandakan bahwa masing-masing ekstrak memiliki kemampuan sebagai antioksidan[14]. Radikal bebas DPPH yang memiliki elektron tidak berpasangan akan memberikan warna ungu. Warna akan berubah menjadi kuning saat elektronnya berpasangan. Perubahan intensitas warna ungu ini terjadi karena adanya peredaman radikal bebas yang dihasilkan oleh bereaksinya molekul DPPH dengan atom hidrogen yang dilepaskan oleh molekul senyawa sampel sehingga terbentuk senyawa difenil pikrilhidrazin dan menyebabkan terjadinya peluruhan warna DPPH dari ungu menjadi kuning. Perubahan warna ini menyebabkan nilai absorbansi menurun pada setiap peningkatan konsentrasi dan terjadi peningkatan nilai \% inhibisi pada setiap ekstrak jantung pisang goroho.

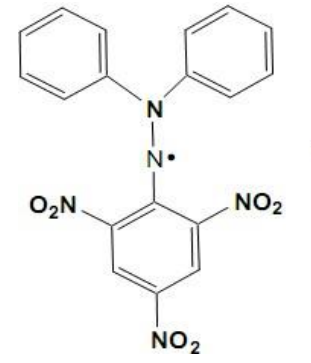

Difenil Pikrilhidrazil (Ungu)

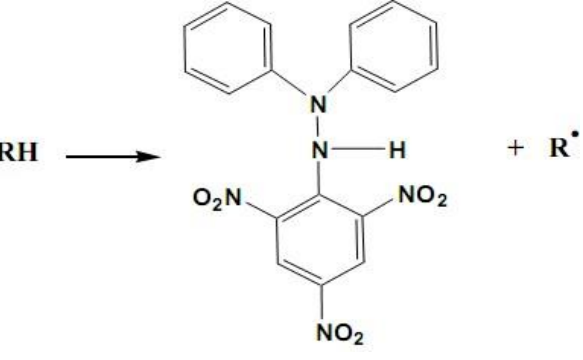

Difenil Pikrilhidrazin (Kuning)

Gambar 1. Reduksi DPPH dari Senyawa Peredam Radikal Bebas [1]

Parameter yang digunakan untuk mengetahui kekuatan antioksidan ialah $\mathrm{IC}_{50}$ (Inhibition Concentration 50 Value). $\mathrm{IC}_{50}$ merupakan konsentrasi yang dapat menghambat aktivitas radikal bebas DPPH sebanyak 50\% [9]. Semakin kecil $\mathrm{IC}_{50}$ menandakan semakin besar aktivitas antioksidan. Hasil uji aktivitas antioksidan jantung pisang goroho (Musa acuminafe L) terdapat perbedaan pada nilai $\mathrm{IC}_{50}$. Perbedaan nilai $\mathrm{IC}_{50}$ antara masing-masing ekstrak jantung pisng goroho (Musa acuuminafe L) diakibatkan oleh kemampuan masing-masing senyawa dalam memberikan elektron kepada DPPH berbeda.

Tabel 3. Nilai $\mathrm{IC}_{50}$ Ekstrak Jantung Pisang Goroho

\begin{tabular}{cc}
\hline Ekstrak & IC $_{50}(\boldsymbol{\mu g} / \mathrm{mL})$ \\
\hline N-heksan & 6,38 \\
Kloroform & 5,48 \\
Etil Asetat & 5,11 \\
Etanol & 4,19 \\
\hline
\end{tabular}

Pada ekstrak etaanol, etil asetat, kloroform dan N-Heksan memiliki nilai persen inhibisi yan baik dan sama-sama memiliki aktivitas antioksidan. Hal ini dimungkinkan karena senyawa metabolit sekunder yang terkandung pada masing-masing ekstrak, pada ektrak etanol memiliki senyawa flavonoid dimana banyak gugus hidroksi $(\mathrm{OH})[15]$. Atom hidrogen dari hidroksi tersebut yang akan didonorkan pada radikal bebas sehingga menjadi stabil. Sedangkan pada ekstrak kloroform memungkinkan terkandung juga senyawa golongan flavonoid dimana menurut [7], agllikon yang kurang polar seperti isoflavon, flavanon, dan flavon serta flavonol yang termetoksilasi cenderung lebih mudah larut dalam pelarut seperti eter dan kloroform, dan pada ekstrak etil asetat diduga memiliki kandungan senyawa alkaloid dan flavonoid yang dikarenakn etil asetat merupakan pelarut semi polar, sedangkan pada ekstrak n-heksan mengandung senyawa alkaloid, dimana mekanisme alkaloid sebagai antioksidan adalah dengan 
cara mendonorkan atom $\mathrm{H}$ pada radikal bebas. Mekanisme ini menunjukkan bahwa alkaloid bekerja sebagai antioksidan primer [5].

4. Kesimpuln

Berdasarkan hasil penelitian yang telah dilakukan dapat ditarik kesimpulan bahwa ekstrak jantung pisang goroho (Musa acuminafe L.) mengandung senyawa alkaloid dan flavonoid serta mempunyai aktivitas antoksidan berturut-turut yaitu ekstrak N-Heksan 4,19 $\mu \mathrm{g} / \mathrm{ml}$, ekstrak klorofor 5,11 $\mu \mathrm{g} / \mathrm{ml}$, ekstrak etil asetat 5,48 $\mu \mathrm{g} / \mathrm{ml}$, dan ekstrak etanol 6,38 $\mu \mathrm{g} / \mathrm{ml}$. Semua nilai $\mathrm{IC}_{50}$ dari masing-masing ekstrak termasuk kategori sangat kuat

Referensi :

[1] Amelia, P. (2011). Isolasi, elusidasi struktur dan uji aktivitas antioksidan senyawa kimia dari daun Garcinia benthami Pierre. Tesis Universitas Indonesia. (Online). (23 Oktober 2012, 10:45).

[2] Asni, A \& Dewi, Y. 2010. Etnofarmakologi Tumbuhan Obat Pada Etnis Bugis Untuk Pengobatan Gangguan Saluran Cerna Dan Identifikasi Farmakognostiknya. Prosiding Seminar Nasional "Eight Star PerformancePharmacist". Yogyakarta.

[3] Athiroh N, Permatasari N, Sargowo D, Widodo MA. (2013) Antioxidative and blood pressure-lowering effects of Scurrula atropurpurea on deoxycorticosterone acetateesalt hypertensive rats. Biomarkers Genomic Med. 2014.

[4] Ditjen POM. (2000). Parameter Standar Umum Ekstrak Tumbuhan Obat. Cetakan Pertama. Jakarta: Departemen Kesehatan RI.

[5] Kurniati Ruth Indah. 2013. Uji Aktivitas Antioksidan Fraksi Etanol Daun Buas-buas (premna cordifolia linn.) dengan Metode DPPH (2,2-difenil-1-pikrilhidrazil). Universitas Tanjungpura:Pontianak.

[6] Mardina, P. Pengaruh Kecepatan Putar Pengaduk dan Waktu Operasi pada Ekstraksi Tannin dari Mahkota Dewa. Jurnal Kimia. 2011; 5(2): 125-132

[7] Markham, K.R., 1988. Cara Mengidentifikasi Flavonoid, diterjemahkan oleh Kosasih Padmawinata, 15, Penerbit ITB: Bandung.

[8] Randy Tampa'I (2019), Penghambatan Reaksi Maillard dari Ekstrak Buah Pisang Goroho Putih (Musa acuminata Colla) Sebagai Pencegahan Diabetes Mellitus. Sekolah Tinggi Ilmu Kesehatan Trinita, Manado

[9] Salamah, N. Aktivitas Antioksidan Ekstrak Metanol Daun Kelengkeng (Euphoria longan (L) Steud.) dengan Metode Penangkapan Radikal 2,2'- Difenil-1-Pikrilhidrazil. Pharmaciana. 2015; 5(1): 25-34.

[10] Siti Maria Ulfa. 2016. Identifikasi dan Uji Aktivitas Senyawa Antioksidan dalam Bekatul dengan Menggunakan Variasi Pelarut. Malang: Universitas Islam Negeri (UIN) Maulana Malik Ibrahim.

[11] Sumardika, I.W., dan Jawi, I.M., 2012, Ekstrak Air Daun Ubi Jalar Ungu Memperbaiki Profil Lipid dan Meningkatkan Kadar SOD Darah Tikus yang diberi Makanan Tinggi Kolesterol, Medicina, 43(2).

[12] Ulfah Sonia. 2016. Uji Aktivitas Antioksidan Ekstrak Daun Rambutan (Nephelium lappaceum) dengan Metode DPPH. UIN Hidayatullah Jakarta. Jakarta.

[13] Vitasari, E W. 2013. Antihiperlipidemia Ekstrak Etanol Batang Kayu Kuning (Arcangelisia flafa (L.) Merr.) Terhadap Tius Putih Galur Wistar Yang Diinduksi Pakan Tinggi Lemak. Skripsi. Sekolah Tinggi Ilmu Farmasi Yayasan Farmasi": Semarang

[14] Youssef, M. M. (2015). Methods for Determining the Antioxidant Activity: A Review Methods for Determining the Antioxidant Activity

[15] Zuhra, C.F., Tarigan, J. \& Sihotang,H. 2008. Aktivitas Antioksidan Senyawa Flavonoid dari Daun Katuk (Sauropus androgumus (L) Merr.). Jurnal Biologi Sumatera. ISSN :19075537.3(1) :7-10 